\title{
DETERMINATION OF TOXIC HEAVY METALS IN
}

\section{CHOCOLATE CONFECTIONERY WRAPPERS \\ USED BY SYRIILANNIKANN CHOCOLATE}

MANUFACTURES AND IT'S MIGRATION TO

\section{CHOCOLATES.}

\author{
By \\ Ranthi Manahari Dias
}

Thesis submitted to the University of Sri Jayewardenepura for the award of the Degree of Master of Science in Food Science and Technology on 2015 


\section{DECLARATION}

The work described in this thesis was carried out by me under the supervision of Dr. (Mrs.) Indira Wickramasinghe and Mr. Namal Dissanayake and a report on this has not been submitted in whole or part to any university or any other institution for another degree/diploma.

0.7.-1.2. 20.15

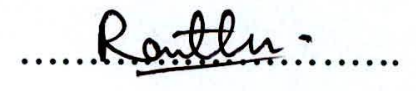

Date

A R M Dias 
We certify that the above statement made by the candidate is true and that this thesis is suitable for submission to the university for the purpose of evaluation.

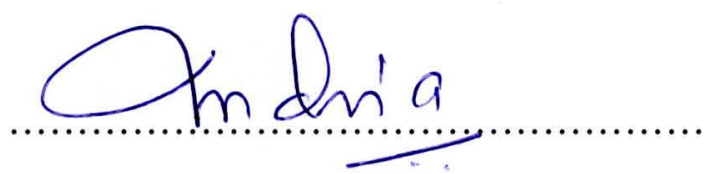

Signature

Supervisor

Dr. (Mrs.) Indira Wickramasinghe

Senior Lecturer / Department of Food Science and Technology

Faculty of Applied Sciences

University of Sri Jayewardenepura

Sri Lanka.

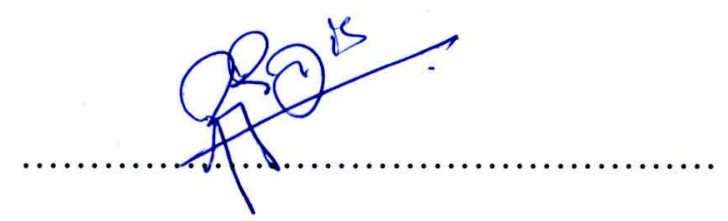

Signature

External Supervisor

Mr. Namal Dissanayake

Laboratory Manager

Intertek Lanka- Soft Line- Analytical Laboratory 


\section{TABLE OF CONTENTS}

Table of contents

List of tables

iii

List of figures

iv

Acknowledgements

v

Abstract

vi

1 Introduction

1

2 Literature Review

2.1 Heavy Metals

2.2 Heavy Metal Toxicity

2.3 Heavy metals present in Chocolates

2.4 Heavy Metals in chocolate wrappers and their migration

2.5 Methods of analysis of heavy metals

2.6 Inductively Coupled Plasma - Mass Spectroscopy (ICP-MS)

3 Materials \& methods

4 Results \& discussion 
5 Conclusions

6 Recommendations

7 References

8 Appendices 
LIST OF TABLES

Table3.1 Microwave heating program for chocolate sample

Table3.2 Microwave heating program for chocolate wrapper

Table 3.3 Preparation of intermediate mix standard solution

Table 3.4 Preparation of working mix standard solutions

Table 3.5 Preparation of internal mix standard solutions

Table 3.6 Masses and Internal Standard for selected metals

For ICP-MS analysis

Table 4.1 Summery of method validationchocolates and wrappers

Table 4.2 Summery of method accuracy

Table 4.3 Concentrations of heavy metals in wrappers

In brand $\mathrm{A} \mathrm{B}$ and $\mathrm{C}$

Table 4.4 Mean concentration of heavy metals in wrappers

Table 4.5 Concentrations of detected metals in chocolates- Brand A

Table 4.6 Concentrations of detected metals in chocolates- Brand B

Table 4.7 Concentrations of detected metals in chocolates- Brand C 


\section{LIST OF FIGURES}

Fig 2.1 Block diagram of ICP-MS

Fig 4.1 Mean concentration of Chromium in wrappers

Fig 4.2 Mean concentration of Nickel in wrappers

Fig 4.3 Mean concentration of Lead in wrappers

Fig 4.4 Mean concentration of Antimony in wrappers

Fig 4.5 Mean concentration of heavy metals in chocolates 


\section{ACKNOWLEDGEMENTS}

My sincere gratitude is extended to Dr. Indira Wickramasinghe, of Department of Food Science and Technology, University of Sri Jayewardenepura, for the guidance and encouragement given to make this task a success.

Generous support extended by Mr. Namal Dissanayake, Laboratory Manager Intertek Lanka- Soft Line- Analytical Laboratory, and the laboratory staff are highly appreciated. This project would not be completed without their support, and guidance, in various stages.

Special thanks are extended to Mr.P.Dias, Senior lecturer, Ms.D.Wijesinghe, Ms.S.Matharaarachchi, Ms.R.Maldeni, and Mr.D.Hettiarachchi of Department of Statistics, all the Academic, Non Academic staff and colleagues of Food Science Department of University of Sri Jayewardenepura.

I would like to express my special gratitude and thanks to industry persons for giving me such attention and time. And at last but not least special thanks are extended towards my parents \& to all my colleagues for their kind co-operation and encouragement during the course of study. 


\title{
DETERMINATION OF TOXIC HEAVY METALS IN CHOCOLATE CONFECTIONERY WRAPPERS USED BY \\ SRI LANKAN CHOCOLATE MANUFACTURES AND IT'S MIGRATION TO CHOCOLATES. AUTHOR'S NAME - RANTHI MANAHARI DIAS
}

\begin{abstract}
Chocolate is one of the most popular confectioneries consumed by all age groups. Among them children are the most attracted group of consuming chocolates and, at the same time the most vulnerable for toxic metals. Toxic metals can accumulate in the body even consumption of small amount of metals, leading to neurotoxic, carcinogenic, and brain disorders. Due to their frequent hand-tomouth behavior, children can be easily ingested by toxic metals. Considering this major risk, it is significant to asses the toxic metals that could be present in chocolates and its wrappers. 48 samples were analyzed to determine the total Chromium, Nickel, Arsenic, Cadmium, Antimony and Lead. Samples were stored under room temperature and refrigerated conditions and acid digested and analyzed by Inductively Coupled Plasma Mass Spectrometry (ICP-MS). Chromium, Nickel, Antimony and Lead were detected in higher concentrations in chocolate confectionary wrappers, and found in low concentrations in chocolates.
\end{abstract}


Arsenic and Cadmium were not detected neither in chocolates nor wrappers. There were no significant difference between the concentrations in room temperature stored chocolates $\left(30-31^{\circ} \mathrm{C}\right)$, and refrigerated chocolates $\left(10-12^{\circ} \mathrm{C}\right)$, but the migration of toxic metals are more favourable in room temperature. 


\section{CHAPTER 1}

\section{INTRODUCTION}

"Chocolate" is a sweet, confectionary of Theobroma cacao seeds. The complex chocolate manufacturing process begins with harvesting fruit of the cocoa tree. The flavor of chocolate differs depending on the ingredients used and the preparation method of chocolate. Chocolate is one of the most popular confectionary consumed by all age groups. Among them children are most preferable groups of consuming chocolates.

Since chocolates are more popular among children, manufactures are very concern about their competitors in the market. Due to this reason the chocolates and other confectionaries are sold in a very attractive manner, wrapped in colourful packaging materials. These packaging materials may contain non-food grade substances, printing inks which can consist toxic substances.

The major danger is with the colourful pigments used in packaging materials. $\mathrm{PbCrO}_{4}$ is an inorganic pigment used in paints and inks. However, most of the countries have prohibited the use of $\mathrm{PbCrO}_{4}$ in food packages (Kim et al., 2008). These toxic substances could have a potency to migrate into the food. 
Major Objective

- To determine the levels of toxic heavy metals in chocolate confectionery wrappers and its migration into chocolates.

Specific objectives,

- To check the levels of total $\mathrm{Cr}, \mathrm{Ni}, \mathrm{As}, \mathrm{Cd}, \mathrm{Sb}$, and $\mathrm{Pb}$ present in chocolate confectionary wrappers used by the Sri Lankan chocolate manufactures.

- To check the migration of $\mathrm{Cr}, \mathrm{Ni}, \mathrm{As}, \mathrm{Cd}, \mathrm{Sb}$, and $\mathrm{Pb}$ into chocolates under two different storage conditions. I.e. Room temperature and Refrigerated conditions. 


\section{CHAPTER 2}

\section{LITERATURE REVIEW}

\subsection{Heavy Metals}

Heavy metals are mixed group of elements with metallic properties which are naturally present in earth's crust. Of the known elements, nearly $80 \%$ are either metals or metalloids. Many metals, in trace amounts, are generally vital to normal physiological processes; for examples, iron in oxygen transport, manganese and selenium in antioxidant system and zinc in metabolism. With these essential metals toxicity occurs when concentrations are either too low or too high.Some metals have no importance and only have the potential to cause toxicity (Inoue KI, 2013). Heavy Metals can be categorized as essential and non essential. Essential metals are those important for normal human health. These metal include iron(Fe), cobalt(Co), copper(Cu), manganese(Mn), molybdenum(Mo), and $\operatorname{zinc}(\mathrm{Zn})$. Essential metals can create a negative impact on human health if they exceed their tolerance limits. Non essential heavy metals are specially toxic metals to human health even in trace levels. They can be accumulate in the body. These metals include lead(Pb), cadmium(Cd), arsenic(As), hexavalent chromium(Cr), mercury(Hg), antimony(Sb) etc(Abhijit, 2014). 


\subsection{Heavy Metal Toxicity}

The effect of metals can be categorized as (i) no symptoms or detectable effects, (ii) stimulatory effects, (iii) therapeutic effects, (iv) toxic to harmful effects, and (v) death. Toxicity of any metal is governed by several factors. They are interaction with essential metal, formation of metal protein complexes, chemical form of the metal element, immune status of the host and age and stage of development of the host. Its electrochemical character and oxidation state, its absorption and transport in body tissues, the stability and solubility of its compounds in body fluids, its case of excretion and reaction with functioning tissues and organelles and with essential metabolites (Abhijit, 2014).

Interaction of toxic metals and essential metals occur when metabolism of toxic metals is similar to that of the essential metal. Lead and Cadmium interact with Calcium in nervous system and skeletal system respectively. Lead replaces the zinc on heme enzymes. Metal protein complexes are formed due to detoxification of toxic metals in the body i.e. Metallothionin form complexes with $\mathrm{Cd}, \mathrm{Zn}$, and $\mathrm{Cu}$ (Klassen, 1996).

Metal can interact with protein leading to an allosteric effect, or with DNA or RNA to stop normal metabolism or with unknown compounds leading to a change in physiologic process. Dietary phosphates also form complexes with heavy metals. Chemical form of the metal determines the distribution of the metal in the body (Abhijit, 2014). 
Continuous exposure to small quantities of metals produces cumulative effects that may result in chronic poisoning with metabolic, nutritional, and neurologic symptoms.

Toxic metals (including excessive levels of essential metals) tend to change biologic structures and systems into irreversible and inflexible conformations leading to deformity or death. For example, acute $\mathrm{Hg}$ toxicities from oral ingestion of $\mathrm{Hg} \mathrm{Cl}_{2}$ causes severe course of nausea, vomiting and diarrhea resulting death due to circulatory failure. Chronic $\mathrm{Hg}$ toxicities cause progressive renal failure with circulatory and neuromuscular abnormalities (Abhijit, 2014).Contamination of food products with heavy metals may cause a serious risk for human health because of the consumption of even small amount of metals can lead to considerable concentrations in human body there leading to biotoxic effects. The biotoxic effects of heavy metals refer to the harmful effects of heavy metals to the body when consumed above the biorecommended limits. The nature of effects could be acute, chronic orsubchronic, neurotoxic, carcinogenic, mutagenic or teratogenic (J.O.Ochuet al., 2012). 